\title{
"Las relaciones jurídicas y los medios de comunicación masiva", desde la perspectiva del derecho internacional privado argentino $^{1}$
}

\author{
Juan José Cerdeira
}

"En homenaje al eximio Profesor Clóvis do Couto e Silva por el valioso aporte que ha significado para el desarrollo del derecho privado en su país y para todos los que estudiamos e investigamos su obra desde la perspectiva internacional comparada."

\section{I) Introducción}

El presente trabajo pretende evaluar la gran repercusión que tienen hoy en día los medios de comunicación masiva en el imaginario popular y como muchas veces esa repercusión afecta a las relaciones jurídicas.

Veremos pues, como esos medios influyen en el derecho y como el hombre común se transforma en protagonista de lo jurídico en desmedro de la normativa vigente y del conocimiento jurídico de los especialistas en el tema.

Algunos casos del Derecho Internacional Privado argentino nos servirán de ejemplo de esta interacción del derecho en la sociedad y de la sociedad en el derecho.

Veremos sobre el final, que responsabilidad cabe a cada uno y quien sale triunfante en cada situación, si es que lo hay.

\footnotetext{
${ }^{1}$ Basado en un trabajo Monográfico del autor presentado en el Doctorado en Derecho Internacional Privado de la Universidad Notarial Argentina.
} 


\section{Primer supuesto:}

Wilner, Eduardo M. c/Osswald, María Gabriela.(C.S. 14-6-95)

El matrimonio argentino Wilner/Osswald se traslada de la Argentina al Canadá, gracias a una beca de estudios que le es otorgada al señor Wilner. Su mujer lo acompaña. En el Canadá nace una hija y el matrimonio luego de algunos años de convivencia en ese país del norte, decide separarse. El juez canadiense otorga la tenencia provisoria al padre y así las cosas, el matrimonio decide venir a pasar las fiestas de fin de año a la Argentina. El señor Wilner debe volver al Canadá por razones laborales y la señora Osswald promete hacerlo después, juntamente con su hija, cosa que no cumple. Es entonces que el padre reclama la vuelta de la menor al Canadá dado que él era el titular de la tenencia precaria de la menor otorgada por el juez canadiense. Basa su reclamo en el articulado de la Convención de La Haya sobre Sustracción Intemacional y Retención Ilegítima de Menores, vigente entre la Argentina y el Canadá.

La madre niega la pretensión, solicitando por su parte la tenencia de la menor ante la justicia argentina.

\section{a) Enfoque del caso desde el Derecho Internacional Privado}

* Desde la óptica del padre, al invocar la Convención de La Haya, solo pretende volver las cosas al estado previo a la supuesta violación del derecho. Esta Convención tiene por finalidad defender al titular de un derecho legítimo sobre un menor, derecho que le es arrebatado por otro pretendido titular de ese derecho.

La Convención no sanciona al ejecutor del acto ni resuelve la legalidad del titulo sino que solo vuelve la situación al estado previo a la violación de su normativa.

La"tenencia precaria" que le otorgara el tribunal canadiense al padre es el justo título del que habla la Convención para accionar su funcionamiento. Por su parte, el viaje conjunto y la retención ilegitima de la menor por la madre, es otro de los argumentos del padre para su reclamo. Finalmente, el traslado al Canadá del domicilio conyugal previo al divorcio, es también razón que podemos situar del lado paterno.

* Desde la perspectiva de la madre, autora de la retención ilegítima, los fundamentos invocados para mantener tal situación, son la inaplicabilidad de la Convención referida, basada en el interés de preservar la integridad física y psíquica de la menor (art. 13 de la Convención de La Haya). Para lograrlo, funda su pretensión ante los tribunales argentinos, en la supuesta denegación del derecho a su defensa en juicio en el Canadá, cuando se le otorgó la tenencia al padre. Otro argumento planteado es el punto de conexión "último 
"Las relaciones jurídicas y los medios de comunicación masiva", desde la perspectiva del derecho internacional privado argentino

domicilio conyugal" que según su posición estaba en la Argentina y no en el Canadá, pues el domicilio canadiense era transitorio por la calidad de becario del padre. El arraigo a las costumbres nacionales y el peligro a la integridad de la menor en un ámbito diferente, sobre todo teniendo en cuenta la corta edad de la menor, son algunas de las excepciones planteadas para avalar su derecho.

En el supuesto planteado, habrá que considerar aplicabilidad al caso de la referida Convención de La Haya. Al respecto, su articulo 20 dice: "la restitución del menor, conforme con lo dispuesto en el articulo 12, podrá denegarse cuando no lo permitan los principios fundamentales del Estado requerido en materia de protección de los derechos humanos y de la libertades fundamentales".

Por lo tanto, si se aplica la Convención de La Haya, el juez interviniente no podrá concluir en sentido contrario a la restitución, sin menoscabar los derechos de la menor. No puede convalidarse que los padres sustraigan a los menores de su jurisdicción natural con el objeto de impedir el acceso del otro progenitor. ${ }^{2}$

El interés superior del menor está protegido, no solo por la Convención de La Haya, sino también por la Convención sobre los Derechos de Niño, que en nuestro país tiene rango constitucional. Por lo tanto cualquier trasgresión a dicha Convención, atentaría contra el orden público argentino.

Un criterio similar al de la Convención de La Itaya, adopta la "Convención Interamericana sobre Restitución Internacional de Menores" (CIDIP IV), que también consagra el principio tradicional de orden público internacional, tendiente a favorecer la cooperación internacional y evitar que se frustren los objetivos perseguidos por la presión de un contexto puramente nacional. ${ }^{3}$

La solución que finalmente resolvió el caso de marras, aplicó la Convención de La Haya en lo estrictamente normológico. Por su parte, desde lo sociológico, se intentó causar el menor daño posible a un angustiante problema familiar que los padres se mostraban incapaces de resolver. Se intentó asegurar de esta manera el mayor nivel de protección al bien jurídico involucrado - la menor - con miras a salvaguardar el orden público internacional y lograr una justa solución al caso.

Los jueces de la Corte Suprema de Justicia de la Nación que dictaron el fallo mayoritatio dijeron: "..la resignación a la invocación del orden público intemo, que la República

\footnotetext{
${ }^{2}$ Osvaldo Onofre Alvarez. Un aporte para el análisis de derecho de familia. El Derecho. Revista del viernes 9 junio de 1995.

${ }^{3}$ Najurieta, María Susana. Orden Publico Internación y Derechos Fundamentales del Niño. La Ley 1997 B pag. 1437 y siguientes.
} 
acepta al comprometerse internacionalmente, es la medida del sacrificio que el Estado debe hacer para satisfacer la recordada Directiva del articulo 11 de la "Convención sobre los Derechos del Niño" y procurar que la vigencia de un tratado de aplicación rápida y eficaz, tenga efectos disuasivos sobre las acciones de los padres que cometen sustracciones o retenciones ilícitas en atropello de los derecho del niño..." 4

\section{b) Enfoque desde la perspectiva del hombre común}

Recordemos a Dante ${ }^{5}$ en aquello que "El derecho es una proporción real y personal de hombre a hombre, que cuando es observado protege a la sociedad y cuando es corrompido la corrompe". Siguiendo este pensamiento deberemos determinar, cual debe ser aquel derecho a ser observado y cuales aspectos deberemos desechar.

El concepto familia podría definirse como una embrionaria célula social. Sin embargo por si sola no iría mas allá de una bella imagen, reflejo viviente de una realidad natural que excede el mero propósito de supervivencia y de procreación de las generaciones humanas. Por otra parte, recordemos que se trata de una institución antiquísima que pese a los avatares liberales y colectivistas continúa modelando y satisfaciendo las necesidades de la vida cotidiana del hombre. De esta forma tendríamos que contemplar a "esta familia" y su posición dentro de una comunidad, tendiendo a evitar el aniquilamiento de posturas individualistas como las que surgen del caso en cuestión.

En el supuesto antes referido, la Sra. Osswald, amparándose en conceptos de familia y de derecho natural, monta todo un escenario para defender su posición, ayudada por los medios de comunicación y por la difusión de su postura.

De esta manera, transforma su pretendida indefensión en el Canadá, en bandera de lucha, argumentando su desdichada vida para lograr la supervivencia y justificar así la negativa a volver al Canadá. Esa "desdichada" vida , la llevaba a "limpiar pisos" en el país del norte mientras que en la República Argentina era mimada por los medios, mostrándola figurada en la imagen de una leona que cuida sus cachorros.

No solo los medios se acercarán a la señora Osswald, sino también conocidos personajes de peso mediático, como fueron la opinión a su favor de destacados representantes del mundo político y deportivo.

El político resguardó su posición diciendo que se trataba de una postura personal y no oficial. Por un parte, el deportista brindó su apoyo llevando a sus hijas a que jugaran con

\footnotetext{
${ }^{4}$ Corte Suprema de Justicia de la Nación, 14 de junio de 1995, caso "W., E.M. c/ .O.,M.G".,JA., 1995 - III - 430 y siguientes.

${ }^{5}$ Dante - MONARQUIA Art. 2 Cap. V.
} 
"Las relaciones jurídicas y los medios de comunicación masiva", desde la perspectiva del derecho internacional privado argentino

la de la señora Osswald, también en señal de confraternidad.

Así las cosas, el caso paso a tomar dominio público y a transformarse en un debate nacional donde opinaban por igual desde las altas esferas del poder hasta la señora de la calle.

La imagen de la pobre leona que cuida a su cachorra y la defiende del terrible monstruo que significa el padre que pretende quitársela, desarraigándola de sus orígenes, de su idioma natural y de su madre, demuestra un humor social muy diferente al que meses después se configurara en otro caso con similares características desde lo jurídico donde el rol de "villana" lo representa una madre española que retiene a su hija ilegítimamente en la lejana España, causando todo el dolor a los sentimientos de un sufrido padre que en la Argentina se veía privado de su hija.

El cambio de humor obedece a que éste sufrido padre no es otro que un popular actor de nuestro país, de gran ascendencia en el público femenino, y no como en el caso anterior un desconocido Eduardo Wilner.

Recordemos entonces una conocida frase que dice: "Cuando la misma pregunta sobre las preferencias políticas se repite en intervalos de tiempo, las respuestas varían sin ninguna base coherente, sino de un modo casual."

\section{c) Política, Justicia y Medios}

La participación de los medios en la vida institucional de un país, y dentro de ésta cuando la mira esta enfocada hacia los tribunales, hace que debamos articular mecanismos para consolidar una nueva interacción entre los medios y la justicia.

La intención es entonces, as egurar que estas dos instituciones contribuyan a fortalecer la democracia y que a la vez acentúen la importancia que conlleva este nuevo papel en que los medios tienen un rol destacado en la vida política nacional.

Sin embargo, en los supuestos que nos ocupan, pareciera producirse un desequilibrio en el peso de ambas instituciones. El uso responsable de los medios masivos se torna fundamental a la hora de buscar el equilibrio señalado. Muchas veces el cambio de escenarios ha generado un reclamo "institucional" como un nuevo mecanismo de control y presión para los jueces.

El uso irracional de este instrumento de presión puede degenerar en situaciones que vayan mas allá de la función guardiana que debe ejercer tanto el periodismo como los demás medios de comunicación. 
Volviendo al supuesto de marras, notamos una influencia del poder político en los medios y de éstos últimos sobre los jueces, con resultados muchas veces inciertos. La previsibilidad jurídica que supone el reclamo judicial, se ve entonces desbordada del marco normativo que la contiene, para adentrarse en un sinuoso camino en que los medios dirigen la opinión e influyen hacia la decisión de los tribunales.

Planteado el caso Wilner, se torna manifiesta la presión de los medios a favor de la madre, e incierta la eventual sentencia que cerrara el caso.

No obstante ello, en un medio periodístico de mucha difusión apareció una noticia que contribuyó a causar mayor confusión en relación al tema. El artículo decía que si la resolución judicial resultaba desfavorable a la restitución, el padre accionaría ante la Corte Internacional de Justicia de La Haya. Nuevamente en este caso se confunden relaciones de derecho privado, como es la restitución de menores, con cuestiones de derecho internacional público, como es el procedimiento ante la Corte Internacional de Justicia, que resuelve cuestiones entre Estados u Organizaciones Internacionales. Lo que debió decir es que el Señor Wilner había interesado al Canadá a defender su caso ante una negativa a la restitución y el Canadá reclamaría ante la Corte de La Haya por incumplimiento de un tratado internacional por parte de la República Argentina.

Como puede verse, es necesario un manejo claro y competente de la difusión de noticias sobre temas específicos, a cargo de personas conocedoras del tema en difusión.

Los riesgos no eran pocos, sobretodo teniendo en cuenta que todo Estado, al vincularse por un convenio internacional, asume responsabilidad internacional en cuanto al cumplimiento del tratado.

La sentencia fue finalmente favorable a la restitución, se cumplió con la Convención, los jueces respetaron el derecho vigente y fallaron en consecuencia. La menor volvió al Canadá, allá se reabrió el juicio por su tenencia, la madre puedo ejercer su derecho a la legitima defensa, mediante un defensor oficial canadiense, y el juez de ese país del norte, falló otorgando la tenencia de la menor a la madre por nueve meses al año y tres meses al año al padre.

Si se quiere el final fue "feliz" y "justo", pero el riesgo y la incertidumbre también fueron grandes.

El peligro del manejo de la opinión como contrapuesta a lo jurídico, subyace. Al caso Wilner le opusimos otro posterior, en donde también los medios, la sociedad, y el hombre común dieron su veredicto antes que los jueces, en este caso a favor del padre. 
"Las relaciones jurídicas y los medios de comunicación masiva", desde la

perspectiva del derecho internacional privado argentino

\section{2) Otros Supuestos:}

Para mayor abundamiento, citaremos otros ejemplos de similares características que si bien no alcanzaron la tremenda difusión de los anteriores, ocuparon buena parte de los medios de la época.

a) Un fallo de la Cámara Nacional de Apelaciones en lo Civil que calificó de ilícito el desplazamiento de un menor hacia nuestro país, realizado por su madre. Se negó la restitución del niño al padre, fundándose también en el citado articulo 20 de la "Convención de La Haya".

Se trataba de un matrimonio que residía en Kuwait donde nació un hijo. A raíz de la guerra del Golfo, la familia huyó y se refugió en Inglaterra, donde el niño comenzó a concurrir a una guardería. Posteriormente, la madre trajo a su hijo a la Argentina sin el consentimiento del padre, invocando el peligro que significaba esa situación para la vida del menor e inició juicio de tenencia en nuestro país. El padre, a través de la Autoridad Central del Reino Unido, promovió demanda de restitución, basándose en la Convención de La Haya.

La madre del niño, el Asesor de Menores y el Fiscal de Cámara argentinos, apelaron la decisión de devolución. Fundaron su apelación en el articulo 206 del Código Civil Argentino $^{6}$, que reputaron principio fundamental del Estado requerido. Si bien la Cámara negó el retorno del niño fue con fundamento en la excepción del articulo 20 de la Convención.

El Tribunal sostuvo que el aludido precepto del Código Civil es solo un principio de derecho de familia argentino, y que los Estados Parte de la Convención han aceptado sacrificar la invocación a los principios de sus derechos de familia.

Sin embargo, reconoce que el derecho a la vida es un objetivo esencial de los Tratados de Derechos Humanos, según dice la "Convención sobre Derechos del Niño". Por lo tanto si se volviera a la situación anterior al traslado ilícito, la vida del niño estaría expuesta a grave riesgo, pues grupos fanáticos habían dictado sentencia de muerte contra su padre. El Tribunal concluyó: "que se debía otorgar preeminencia a la protección contra un grave riesgo de vida, que en el caso parecía verosímil".

Puede apreciarse entonces, que en esta sentencia, sin apartarse del derecho, los Tribunales preservaron los valores supremos, en cuya cúspide se encuentra el derecho a la

'Art.206: "Separados por sentencia firme, cada uno de los cónyuges podrá fijar libremente su domicilio o residencia. Si tuviese hijos de ambos a su cargo se aplicarán las disposiciones relativas al régimen de la patria potestad. Los hijos menores de 5 años quedarán a cargo de la madre, salvo causas graves que afecten el interés del menor. Los mayores de esa edad a falta de acuerdo de los cónyuges, quedarán a cargo de aquel a quien el juez considere más idóneo..." 
vida, su integridad y sus dignidad. Muestra también un delicado equilibrio entre el rígido derecho interno en materia de menores y los imperativos de las obligaciones asumidas internacionalmente en materias como las tratadas, en que ningún Estado puede combatir el flagelo de los secuestros de manera aislada.

b) Un padre y sus hijos, todos australianos, vinieron a Buenos Aires y se quedaron a vivir aquí. Al pedir la radicación en nuestro país, se le exigió la autorización de la madre quien vivía en Hong Kong y pretendía recuperar a sus hijos rápidamente. Para lograrlo, pidió ayuda al Consulado argentino en esa ciudad y al "periodismo". La madre contaba a su favor con un fallo de un tribunal de Hong Kong y exigía el cumplimiento de la Convención de La Haya. La ,por entonces colonia británica, no era parte la referida Convención. El matrimonio se encontraba separado desde hacía seis años. Ambos padres tenían la tenencia compartida de los hijos hasta los 18 años.

La difusión periodística del fallo no escatimaba en frondosos relatos de la azarosa vida de uno y otro progenitor, pasando desde las disputas económicas hasta las conductas irregulares de uno y otro padre.

Lo llamativo del caso fue, nuevamente, la intención del despliegue periodístico para lograr presionar y obtener una sentencia en favor de una u otra parte. En el caso se cuestionaron, entre otros, temas como la radicación, la tenencia, y la autorización de viaje.

Ante un asunto eminentemente controversial, que debería resolverse en los estrados judiciales, se mezclaron cuestiones de diferente tipo, a la par que se cuestionó el proceder de la Cancillería como Autoridad de Aplicación y se pretendió, a través de la difusión periodística, el logro de soluciones en un determinado sentido. La situación se vio coronada por las presuntas "dificultades" que tendría que sortear el Canciller argentino en su visita a Hong Kong, a la hora de responder ante 7000 periodistas que estarían en la isla con motivo del traspaso de la soberanía británica a la China. ${ }^{?}$

c) Un cordobés, separado, con derecho de visita sobre su hijo se entera al pretender retirarlo de un cumpleaños, que su madre se lo había llevado a los Estados Unidos. A partir de ese momento, se inicia una odisea de tramites burocráticos, desencuentros e intervenciones judiciales.

Dos años mas tarde, el padre toma conocimiento que si bien la primera escala del viaje fue la Florida (Estados Unidos), en ese momento la residencia de madre e hijo era Pforzheim, una pequeña ciudad a sesenta kilómetros de Stuttgart (Alemania).

${ }^{7}$ El Clarín jueves 12 de junio de 1997 pág. 6 y 67. 
"Las relaciones jurídicas y los medios de comunicación masiva", desde la perspectiva del derecho internacional privado argentino

La madre, de raza negra y ciudadanía europea, argumentaba un previo intento de secuestro del padre como motivo de sus actitudes anteriores a su divorcio cordobés.

Ante la intervención judicial, los resultados practicados sobre el menor en Alemania demostraron la total adaptación del niño a ese entorno (aspecto que desactivaría la aplicación de la Convención de La Haya, o sea el respeto por el interés del menor) y la consiguiente permanencia del menor con su madre. ${ }^{8}$

d) Una nacional noruega retiene ilegalmente a su hijo en Oslo, privando a su padre argentino de los derechos sobre el niño.

Iniciado el juicio ante un tribunal noruego cercano a Oslo, la Corte de Apelaciones de Noruega falló a favor del padre, obligando a la mujer a restituir al chico al país de origen. La restitución del menor se efectúa nuevamente en el marco de la citada Convención de La Haya. ${ }^{9}$

Dentro de los aspectos curiosos que merecen destacarse en torno a los supuestos referidos, cabe comentar que a partir del caso testigo referido en primer lugar, la presión ejercida para su solución, consiguió un decreto presidencial (el numero 891/95 del fondo de ayuda económica para la asistencia legal en el exterior, creado por el gobierno a partir del citado caso).

En consecuencia, la mayoría de los casos de restitución que ocurren en la Republica son resueltos en el marco de la citada Convención de La Haya y utilizando el dinero de este fondo.

Otro tema que también debe mencionarse en torno al primer caso referido es el de la tremenda exposición a la quedaron sometidos los funcionarios que conforman la Autoridad Central nacional. Efectivamente, la descarnada cobertura periodística de ese primer caso testigo llevó a que funcionarios de la Autoridad Central fueran citados en los Tribunales para responder acerca de la responsabilidad de los actos ejecutados en el marco del cumplimiento de sus funciones y respeto a la normativa vigente. Sibien finalmente no fueron encontrados cargos contra ellos, se demuestra una vez más los efectos perniciosos a los que puede llevar una inadecuada información o cobertura de temas que se entienden netamente jurídicos.

Desde 1994 en adelante la Cancillería intervino en numerosos pedidos de restitución de menores, ya sea para que los menores vuelvan a la Argentina u a otros países donde

${ }^{8}$ El Clarín viernes 20 de junio de 1997 pag. 34.

${ }^{\circ}$ El Clarín jueves 5 de marzo de 1998 pag. 46. 
vivían habitualmente. Sólo en 1996, 17 chicos regresaron a la Argentina después de haber sido trasladados sin el consentimiento de alguno de los padres.

Todos los casos descriptos en este trabajo alcanzaron repercusión periodística, significando este un nuevo aditamento de singulares características extra jurídicas que va más allá del marco legal vigente para la consecución de sus propósitos.

\section{3) Caso Arias Uriburu:}

Unos años después, otro caso, también de sustracción internacional de menores, tomó estado público por la participación de la política y de los medios.

Es el caso de una ciudadana argentina, casada en Guatemala con un ciudadano jordano y tres hijos nacidos de ese matrimonio en Guatemala .

Repentinamente, el padre sustrae a los menores y se los lleva a Jordania, dejando a la madre desesperada sin sus hijos.

Visto el caso iusprivatista intemacional, la fuente que resulta aplicable en defensa de los menores y del interés de la madre sobre ellos, es la Convención de las Naciones Unidas sobre los Derechos del Niño, ratificada por Guatemala y el Reino de Jordania.

En este caso, no vincula la Convención de La Haya sobre Sustracción de Menores, por lo tanto, habrá que remitirse para su análisis, a la otra fuente aplicable, tomando en. cuenta la protección del bienestar de los menores que fueron separados de su madre, ya que la Convención sobre Derechos del Niño no se ocupa de casos de sustracción o retención ilegitima de menores.

Técnicamente, el domicilio conyugal estaba en Guatemala, los menores eran guatemaltecos, por lo tanto cualquier acción relativa a ellos debía entablarse ante los tribunales locales. Así se hace y son los tribunales de la República de Guatemala quienes por medio del auxilio judicial internacional, reclaman a los menores a sus pares de Jordania.

En atención a que mucho no se avanza en esa acción, principalmente por el silencio de los jueces jordanos, es que la madre suma a la vía estrictamente jurídica, otra que pueda darle una respuesta más satisfactoria a su problema.

En ese sentido, y amparada en su descsperación, resulta a su favor su calidad de argentina, hija de un prestigioso diplomático de este país, que fuera embajador ante Guatemala, Por su parte, cabe considerar, que ante la ausencia de soluciones en el derecho extranjero, los tribunales argentinos pueden intervenir en favor de la defensa de los derechos 

pers pectiva del derecho internacional privado argentino de sus nacionales.

Pero no será estrictamente el camino de los Tribunales argentinos, los elegidos por la desesperada madre, sino los contactos que el padre puede procurarle. Además de ello, nuevamente los medios de difusión masiva cobren un rol protagónico en ayuda de la madre.

Es entonces cuando empiezan a confundirse nuevamente los remedios jurídicos en un caso internacional, con los remedios de otra índole, aportados por las vinculaciones de un padre con llegadas a las altas esferas del poder.

La madre visita, entonces, programas televisivos en la Republica Argentina, consigue que el primer mandatario haga gestiones de buena voluntad en su favor ante el rey jordano y que una conocida empresaria argentina escriba una carta, de madre a madre, a la reina de Jordania. Como se verá, nuevamente lo jurídico queda relegado a un plano secundario en la lejana disputa entre los tribunales guatemaltecos y los jordanos.

Tanta presión, parece empezar a surtir su efecto, al punto tal que el embajador jordano ante la Asamblea de las Naciones Unidas, acepta recibir a la madre para escuchar sus caso.

La difusión de tal noticia, sin una sola aclaración al respecto, se estima altamente negativa para aquellos otros sujetos que puedan verse involucrados en situaciones similares y que les resulte imposible llegar a las esferas antes mencionadas.

La obvia aclaración sería, que la Asamblea General de las Naciones Unidas se ocupa de cuestiones que involucran a Estados u Organizaciones Internacionales, y no de los casos de madres a quienes les sustraen a sus hijos.

Cabría preguntarse entonces, si a una señora de un remoto pueblo de la Puna argentina, y casada con un boliviano, que le fueran quitados sus vástagos, podría ir a reclamar ante las Naciones Unidas para su restitución.

Mayor agravante a esta situación, son manifestaciones hechas por la propia madre, en sentido de que se haría uma reunión entre las "tres partes interesadas."

Esas tres partes serian, Guatemala, Jordania y la Argentina. Cabría preguntarse ¿La Argentina, en calidad de qué?

Dicha aseveración fue hecha en un conocido programa televisivo de los mediodias, y la conductora del mismo brindó por la valentía de la madre que protege en cualquier nivel que sea, el amor hacia sus hijos. 
Obviamente, alguien tendría que aclarar la Argentina como país no tiene ninguna vinculación con el caso, en todo caso debería haberse hecho una presentación ante nuestros tribunales. Por otro lado, pareciera que nadie se dio cuenta que la posibilidad de defensa y lucha de la madre, solo se debe a sus aceitados contactos con el mundo diplomático.

La cuestión, a la fecha, sigue sin resolverse de hecho. Los tribunales guatemaltecos fallaron a favor de los derechos de la madre, pero lo cierto es que los hijos siguen en Jordania con el padre y que las pocas veces que la madre pudo visitarlos, siempre fue con representantes legales de los gobiernos guatemalteco, jordano y $\underline{\text { iargentino! }}$

La defensa de los derechos de una madre hacia sus hijos es clara, esta madre los tiene todos, pero que ocurre con todas otras aquellas madres que en similares características por no tener un padre diplomático, ni posibilidad de acceder a los medios de comunicación, ven frustrados sus derechos.

El peligro de la desigualdad ante la ley, entre ciudadanos de primera y de segunda, parecería entonces evidente. La difusión de estos mediáticos casos que conllevan alto "rating", pueden defraudar las lógicas expectativas de otras personas en casos parecidos.

\section{4) El papel de los medios}

Como vemos, el papel de los medios cobra gran relevancia en nuestra sociedad actual. Los casos referidos son recientes, conocidos, y curiosos. En ellos, las consideraciones jurídicas corren al margen de lo principal. Lo principal pareciera ser aquella solución inducida desde un grupo de personas los que dirigen algunos medios de comunicación, y el rédito que a éstos puede producirles una decisión en un sentido u otro.

Poco importa entonces aclarar, donde deben ventilarse los problemas jurídicos o quienes son los interlocutores validos para el análisis de esas situaciones.

Los medios de comunicación son un mecanismo dinámico e inagotable, que a partir de sus propias necesidades, transmiten y construyen visiones del mundo, de la familia y de la sociedad y a su vez, determinan los modos en que los receptores se relacionan con ellos. ${ }^{10}$

La incorporación de los medios en el proceso de la percepción de la realidad de los individuos y del imaginario social, expande el universo autor referencial y lo sustituye por la supremacía de la heterogeneidad y la diversidad.

\footnotetext{
'Gorvein, Nilda S. y Polakiewicz, Marta: El Poder de los Medios Masivos de Comunicación. El cuarto poder. Ediar, 1999.
} 
"Las relaciones jurídicas y los medios de comunicación masiva", desde la perspectiva del derecho internacional privado argentino

Toda realidad es una construcción de aquellos que se esfuerzan por descubrirla e investigarla. El sentido común supone que la realidad puede ser descubierta y que una realidad inventada jamás puede ser la auténtica realidad. El constructivismo, en cambio, parte de la premisa de que toda realidad es la construcción de aquello que se intenta descubrir e investigar"."

La transmisión de modelos culturales y sociales que los medios de comunicación efectúan, afecta también a muchas otras cuestiones. Sin perjuicio de la variedad de los mensajes transmitidos, subsisten aún en los contenidos de la programación y la publicidad, modelos que pueden llevar a un fin no perseguido, como son la desigualdad, la descalificación y la discriminación. Ejemplo de esta ultima afirmación lo constituyen los modelos representativos de cuadros de anorexia, modelos de éxito, de determinados status, marcas que se identifican con ciertas imágenes, cuadros de corrupción, estimulación de las dependencias, como el consumo del alcohol, el tabaco, etc.

En el caso especifico que nos aboca, podemos llegar a encontrarnos con desigualdad y discriminación de trato entre una madre con acceso a determinadas salidas a su desesperación que no podrán ser las mismas que las de otra madre que carezca de las vinculaciones de la primera.

Alguna vez se ha dicho que los medios de comunicación masiva, deberían educar al hombre común, y si no fuere así, por lo menos no tendrían que enfrentarlo ante realidades que jamás serían suyas.

El riesgo es que ante cada nuevo caso en que se interrelacionen valores que no debieron relacionarse, jamás sepamos cual será el fin de la historia.

No debemos olvidar que uno de los objetivos en el camino hacia la justicia, es el de la seguridad jurídica. Esa seguridad jurídica se basa en el cumplimiento de las normas vigentes. Si dejamos a éstas normas de lado y escuchamos las voces del sentir popular, difícilmente nos acerquemos a la previsibilidad y por ende dificultaremos la llegada a una solución justa y equitativa.

Una propuesta válida debería fundarse básicamente en la convicción de que la igualdad, la justicia y la solidaridad, son ideales de vida.

Tales valores parecen todavía una asignatura pendiente de nuestra sociedad. Restaría aún modificar múltiples y diversas actitudes, comportamientos, horizontes valorativos, estructuras sociales y evaluaciones referenciales, que impiden o postergan el libre desarrollo,

11 Watzlawick, Paul y otros: La Realidad Inventada, Gedisa. 1990 
posibilidades y potencialidades de realización y participación de vastos sectores de la sociedad en los que, sin duda alguna, los medios de comunicación tienen un papel fundamental en la formación de paradigmas y modelos sociales que inciden en las conductas individuales.

Habría que adoptar entonces, un criterio que consagrara principios fundamentales como el respeto a los derechos humanos, las libertades individ uales, la no discriminación, la igualdad entre varones y mujeres, el respeto por la diversidad, por los intereses y necesidades de las personas en función de sus características personales, edad, desarrollo evolutivo, respetando la autonomía responsable de todos los sujetos que intervienen en la compleja relación que se establece entre los medios de comunicación, la sociedad y el Estado. ${ }^{12}$

La superación del paradigma vigente implicaría que los medios desarrollaran un servicio pedagógico y preventivo, que además permitiera un derecho a replica social, elementos estos necesarios para una verdadera interacción en materia de comunicación humana.

Una de las cuestiones de las que tendríamos que ocuparnos, sería entonces, la de "la opinión publica", su valor y los elementos que contribuyen a su formación.

Recordemos que "si la democracia tuviera que ser un sistema de gobierno guiado y controlado por la opinión de los gobernados, entonces la pregunta que nos deberíamos replantear es: ¿Cómo nace y cómo se forma una opinión publica?"13

Sería de interés entonces, averiguar cómo se constituye una opinión publica autónoma que sea verdaderamente del publico. Tengamos en cuenta que cuanto más se abre y se expone una opinión publica a flujos de información exógenos (que recibe del poder político o de instrumentos de información de masas) mas corre el riesgo de convertirse en "hétero-dirigida".

La prensa, la radio y más aún la televisión, fueron suplantando el acto de discurrir. La fuerza arrolladora de la imagen, rompe el sistema de reequilibrios y retroacciones múltiples que se habían instituido durante casi dos siglos, los estados de opinión difusos que desde el siglo XVIII fueron denominados de opinión publica.

Los sondeos de opinión consisten en respuestas que se dan a preguntas, generalmente formuladas por un sujeto interpelador: Esta definición es la contestación a dos cosas: una,

\footnotetext{
${ }^{12}$ Gorvein, Nilda S. y Polakiewicz, Marta: El Poder de los Medios Masivos de Comunicación. El cuarto poder. Ediar, 1999,

is Sartori Glovanni. Homo videns. La sociedad teledirigida. Ed. Turus Madrid 1998.
} 
"Las relaciones juridicas y los medios de comunicación masiva", desde la perspectiva del derecho internacional privado argentino

que las respuestas dependen ampliamente del modo en que se formulan (y por lo tanto de quien las formula), y otra, que frecuentemente el que responde se siente forzado a clar una respuesta improvisada. iEs ese el pensar popular?. De hecho, la mayoría de las opiniones recogidas son : a) Débiles (no jugadas); b) Volátiles (pueden cambiar en poco tiempo); c) Inventadas (para no quedar mal diciendo "no sé"); y d) Con efecto reflectante (rebote de lo que sostienen los medios de comunicación).

El problema de la fácil manipulación de los sondeos, dependerá de la forma en que se realice la pregunta, ya que una misma pregunta puede presentarse desde diferente perspectiva, induciendo la respuesta.

Por ejemplo, no es lo mismo preguntar si se debe permitir el aborto o bien si se debe proteger el derecho a la vida. ${ }^{14}$

Cabría referirse también, a la cuestión "imagen", en la que la televisión tiene mayor fuerza de llegada. En el primero de los supuestos referidos (Caso Wilner), la imagen utilizada por el entrevistador de la leona con los cachorros como soporte a la fundamentación de la posición materna en el caso, fue de gran impacto mediático. Si a esa imagen le sumamos el carisma "intelectual" del entevistador, potenciamos ambos efectos.

Una pregunta que es menester preguntarse es ¿Qué responsabilidad le cabe a los medios de prensa en la formación de la opinión? Hemos notado en los casos referidos confusión y perturbación. La verdad de los hechos habría que rastrearla y enseñarla. Recién entonces y podría inquirirse acerca de los distintos pareceres que surjan como producto de la información recogida. Ni el hombre común, ni el jurista tendrán por si solos la respuesta absoluta y adecuada ante un hecho determinado. Por eso decimos que los medios deberían buscar la verdad mediante una investigación aséptica de los acontecimientos, una valoración que involucre a los diversos actores sociales y jurídicos y que finalmente tienda a que ambos descubran el camino hacia la justicia.

Deberíamos recordar aquella frase:"...que por molicie o por obra de los intereses creados, la crítica que higieniza, es menos frecuente y mas difícil de ser practicada de lo que se supone".

Por otra parte el "prestigio" de ciertos hombres de ciencia - iconos mediáticos hacen que sus opiniones, en ocasiones verdaderamente disparatadas, tengan mucho peso en la formación del pensamiento colectivo, base de la opinión publica. ${ }^{15}$

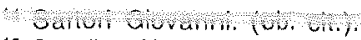

${ }^{15}$ Sandler, Hector: Algunas delicadas cuestiones entorno a la libertad de prensa. El cuarto poder, Ediar 1999.
} 
Con relación a lo antedicho podríamos ampliar el concepto y extenderlo no solo a los hombres de ciencia, sino también a los políticos, deportistas, actores y en general a todos los responsables de la formación de opinión, como periodistas, locutores televisivos y radiales y aún animadores de programas de gran repercusión.

\section{5) Conclusiones:}

Finalmente, cabría esbozar una propuesta para encarrilar aquellos supuestos que, ante asuntos como los referidos-casos iusprivatistas multinacionales-cobran una especial difusión por el contenido altamente emocional de sus planteos y que llegan al ruedo popular acompañados de opiniones mediáticas.

La propuesta consistiría en acompañar los planteos con una información adecuada y neutral de los hechos y permitir una réplica autorizada con igual difusión que la primera, para que en caso de generarse un debate, éste sea limpio y técnico.

En aquellos casos de supuestos que deben resolverse en el ámbito jurídico- judicial y que por distintas razones alcanzan otros campos de difusión, deberían ser los juristas, doctrinarios, educadores y especialistas en el tema, los que tomen la responsabilidad de acompañar la información aportada por los responsables de medios de comunicación masiva.

Esa responsabilidad compartida podría contribuir a avanzar en la formación colectiva de la sociedad y a reconstituir y preservar el respeto por el derecho. 
Cadernos do Programa de Pós-Graduação
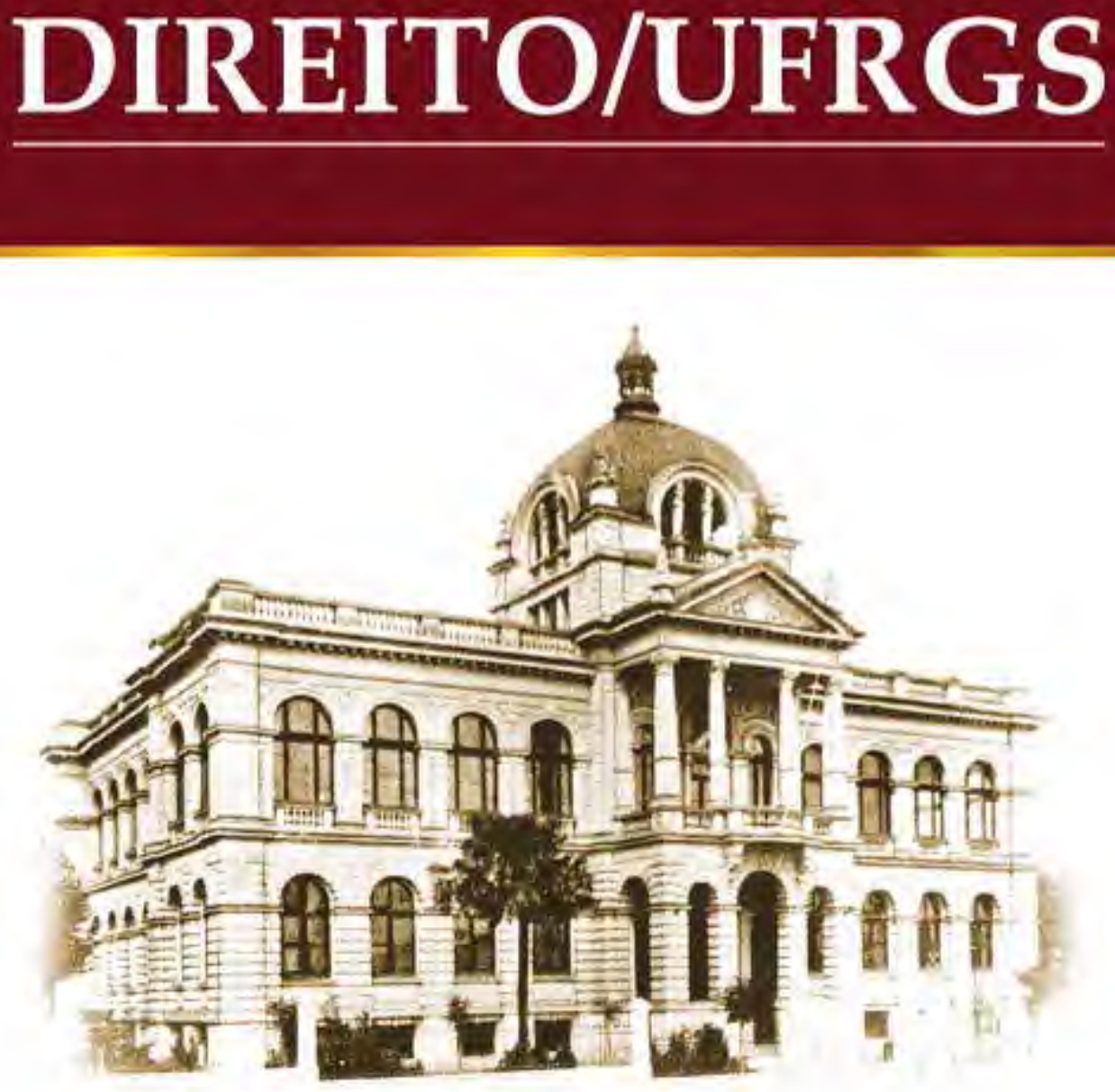

Cadernos do Programa de Pós-Graduação em Direito, Número 1, Março de 2004. Publicação da edição digitalizada em 15 de Janeiro de 2015. 